\title{
Application of Personalized Library and Information Services in Chinese University Libraries
}

\author{
Luo Xin \\ School of Business Administration, South China University of Technology, Guangdong Guangzhou, China \\ luoxin@scut.edu.cn
}

Keywords: University library; Personalized service; Readers' needs; Information service

\begin{abstract}
With the development of modern communication technology and the improvement of the overall cultural level of the society, users' personalized information demands make it difficult to maintain the traditional information delivery mode of university libraries. This paper analyzes the practice and application of personalized service in Chinese universities and colleges, and finds that there are many deficiencies. This paper puts forward the corresponding countermeasure to realize the individualized service of university library. Only continuous improvement of library services can better satisfy the readers' personalized needs and provide readers with better services.
\end{abstract}

\section{Background of personalized information service in university libraries}

In 1979, the American scholar Patricia Glass Schuman put forward the idea that "libraries and information providers should provide new services that cater to individual needs" [1], a prototype for personalized information service ideas. Morgan Eric Lease defined library personalized service, hung on the site of the American library association, think that the library personalized service "is a kind of user driven, can be customized information service, which allows the user to create a convenient web page, the list will be available from the library information resources." [2]

In the contemporary information society, people in both social life or consumption demand, in the teaching and research or individual learning, and even values, are reflected from single to multiple, from integration to differentiation, from the demand for information to the development trend of the demand for knowledge, and so on, namely under the network environment, the user's information demand is more and more to develop in the direction of individuation.

For the traditional college library service model, the information is not distinguishable from the users, and all users see the same information provided by the system. For each user, finding the information you need is like looking for a needle in a haystack. Therefore, with the increasing amount of information, the user personalized information demand makes the traditional information delivery mode of university library hard to maintain. At the same time, the communication mode of network interaction and the universal application of real-time feedback mechanism make it possible for information service organizations to provide personalized information needs of users. That is, it is possible for university libraries to change from traditional service mode "users searching for information" to "information seeking users".

In recent years, many scholars have carried out relevant researches, mainly about library and information. Jacintha Ukamaka Eze found out the problematic factors in providing library and information services to Nigeria prisoners and the strategies for solving them [3].Kay Neville examined the issue of marketing university library and information services using a variety of real life examples from academics, researchers and library practitioners around the world [4]. Joanne Gard Marshall explored library and information service impact on patient care quality [5].

University library individualized information service, can according to user selection and feedback, timely and perfect the construction of library, exert the maximum utility of information, put an end to purchase "dormant" resources, improve the utilization rate of collection. It can improve service quality and efficiency according to user's suggestion. For users, the ability of information retrieval can be improved, and the time and energy of searching information can be 
saved to develop their latent abilities and qualities. Therefore, the provision of personalized service of university library is not only the inevitable requirement of information technology progress, but also the embodiment of the concept of "customer first" service.

This paper analyzes the practice and application of personalized service in Chinese universities and colleges, and finds that there are many deficiencies. This paper puts forward the corresponding countermeasure to realize the individualized service of university library. Only continuous improvement of library services can better satisfy the readers' personalized needs and provide readers with better services.

\section{The practice and application of personalized information service in university libraries}

At present, the proportion of Chinese university libraries offering personalized service is not large, and it is mainly provided in the following three forms:

- Provide personalized services through self-developed systems. Such as the personalized information service system of the digital library of Renmin university of China, the library of Zhejiang university library "my library" system.

- Carry out personalized information service through ILAS system. Sun yat-sen university library, Wuhan university library, south China agricultural university library, etc.

- Carry out personalized information service through the management system of Huiwen library.

In practice, there are many problems in the individualized information services, and there are many deficiencies. The system of self-development and the management system of Huiwen library are relatively unitary in the function of personalized information service. ILAS II relatively perfect system to provide personalized service function, but also exist some problems:

\subsection{The user model is not well established.}

There is no user survey, such as ILAS system only select the category of interest when registering, and it is only a major category of Chinese library classification. If the user's research direction or interest subject has changed, there is no warning to users to modify the system of interested subjects. At the same time, the user will not be able to change the registration information voluntarily. This user will not be able to enjoy the personalized information service of the library. If the data mining technology can be used automatically, the user's browsing, searching and borrowing information can be used to find the direction of user interest, which will make the user more willing to use the personalized service function.

\subsection{The "new book recommendation" is rough.}

In the personalized information service system, there is no classification mechanism for the new book recommendation, but only in batches. If it can be pushed according to personalized customization, it should be more popular with users. However, in the existing system implementation of such push mode, the library needs to pay more to practice.

\subsection{The recommended function of "interested new book" is also rough.}

Because the system is not accurate enough to collect the user's interest information, the system has recommended too many books to users. The information is too loud, which makes it difficult for users to browse. In addition, the system does not provide interest book management features, don't allow the user to delete management to push catalog, so that users can only repeat STH in a large number of useful or useless information. All this makes the personalized service less efficient and difficult to play its due role.

\subsection{Users cannot select personalized services.}

For personalized services, optional, targeted, and customizable are the main features. But the existing library personalized service system, in this aspect is obviously insufficient. The system provides all services, all information to the user. Users can't choose which items they need, which ones they don't need. 
In general, ILASI II provides personalized service function is quite simple. In the "interested new book" section, users can personalize the book category, but it's too crude. This feature does not make much sense today when you can easily retrieve books by category. Other functions only integrate the traditional service project of university library through the web page. The personalized features are not obvious and there is no further personalized service.

\section{The factors restricting the practice and application of individualized information service in Chinese university libraries}

Compared with the research on the individualized service of university library, the practice and application of personalized service are obviously lagging behind and still in the practice exploration stage. In general, there are three main factors that influence the application of personalized service in university libraries:

\subsection{Running mechanism.}

In the continuous improvement of the management system of university libraries in China, there is a lack of unified coordination mechanism, and the progress of resource sharing plan is difficult and slow. At the same time, schools, providing free services on campus, thus neglecting economic benefits, basically fund the university libraries in China and libraries lack the motivation to develop themselves.

\subsection{Staff quality.}

Personalized service is not simply to push information to users, but a deep information service. It needs staff to have good service concept and service consciousness, have strong computer, network, communication and other technical ability. Most importantly, the staff has strong interpersonal communication skills, which can bring the library closer to the user so that the information needs of users can be understood in time. These are the basis of personalized information service in libraries.

\subsection{The user.}

The premise of personalized service is that the service provided is what the user expects. Library staff can better provide information about what they need, only if they know what they need. However, the current information consciousness of library users, the ability to acquire, utilize and discriminate information needs to be strengthened.

\subsection{Resource building.}

With the development of information technology, libraries now provide resources not only for books, but also for network dynamic information, compact discs, electronic databases and so on. However, the Chinese university library is generally shallow in the processing of various kinds of resources. Shortcomings such as content intersection, information redundancy, low relevance, and inaccurate organization description affect the user's use of information.

\subsection{Privacy protection.}

To better carry out personalized services, libraries inevitably need to collect personal information about users, which involves user privacy issues. At present, because the individualized service of university library is mainly aimed at scientific research purpose, there are few issues concerning user privacy protection.

\section{Countermeasures for the practice and application of personalized information service in university libraries}

The university library needs to strengthen the inter-library cooperation, improve the resource contribution and enhance the motivation of personalized service. For example, establish the operation mechanism of input and benefit and implement some paid services. This can pay attention 
to social benefits and economic benefits. Set up the concept of "running the library", conduct competition among the libraries, and improve the strain capacity and innovation consciousness of library staff. To be user first, offer personalized service to users.

Create a personalized service team consisting of different departments, including leadership, implementation layer and technology layer. The leadership is responsible for providing macro guidance. The implementation layer is the core of the team, and the provision of personalized services mainly depends on the efforts of the staff. The technical layer provides technical support for personalized services.

Subject librarian system is necessary to carry out personalized service. The subject librarian system will be further promoted through external introduction, internal mining and other means of selecting and training subject librarians. At the same time, strengthen the construction of staff, train staff, and enable them to learn computer, network and other information retrieval techniques, and interpersonal communication skills.

Conduct more user behavior research and strengthen user training. Personalized services must consider users' habitual problems, and the university library needs to help and guide users to get used to the personalized service provided by the library. At the same time, we must strengthen the research on library users. According to the user's knowledge structure and behavior way, the user personalized information demand and behavior rule of different subjects, age and environment are explored. In this way, we explore the way users make decisions in information activities, and organize the information navigation retrieval and utilization mechanism for each user.

Focus on integration of resources and services. On the one hand, it integrates the existing information resources to form an integrated information system. On the other hand, integrate user information, build user information base, realize the mapping between user information requirements and system resources, and extract knowledge to users according to user demand.

In conclusion, the current practice and application of personalized information service in university libraries in China is still very small in scale, and it needs to be further developed and applied.

\section{Acknowledgments}

The research is financially supported by Guangzhou Association for Science\& Technology of China (Grant No. K2017020201002).

\section{References}

[1] Patricia Glass Schuman: Library and information services for meeting Personal needs: a discussion guide. Washington, D. C.: National Commission on Libraries and Information Science, 1979.

[2] Morgan Eric Lease: My Library: A Model for Implementing a User centered, Customizable Interface to a Library's Collection of Information Resources. Raleigh, NC: Digital Library Initiatives, 1999.

[3] Jacintha Ukamaka Eze, (2015) "Problems and prospects of providing library and information services to the prisoners in Nigeria", Library Review, Vol. 64 Issue: 4/5, pp.285-304.

[4] Kay Neville, (2014) "Marketing Library and Information Services II: A Global Outlook", Library Review, Vol. 63 Issue: 1/2, pp.165-166, https://doi.org/10.1108/LR-10-2013-0122

[5] Joanne Gard Marshall, Jennifer Craft Morgan, Cheryl A. Thompson, Amber L. Wells, (2014) "Library and information services: impact on patient care quality", International Journal of Health Care Quality Assurance, Vol. 27 Issue: 8, pp.672-683, https://doi.org /10.1108 /IJHCQA- 10-20130119 